\title{
Co-localisation of prostaglandin endoperoxide synthase and immunoreactive adrenocorticotrophic hormone in ovine foetal pituitary
}

\author{
S K Reimsnider and C E Wood
}

Department of Physiology and Functional Genomics, PO Box 100274, University of Florida College of Medicine, Gainesville, Florida 32610-0274, USA

(Requests for offprints should be addressed to S K Reimsnider; Email: sharonr@phys.med.ufl.edu)

\begin{abstract}
Previous studies have shown that both an intact hypothalamic-pituitary-adrenal axis and prostaglandin $\mathrm{E}_{2}$ $\left(\mathrm{PGE}_{2}\right)$ are involved in the timing of parturition in sheep. $\mathrm{PGE}_{2}$ is known to be synthesised by the placenta but has also been found in the foetal brain and pituitary. We propose that the enzymes necessary for production of $\mathrm{PGE}_{2}$ are found in the ovine foetal pituitary and may be able to exert an autocrine and/or paracrine influence on corticotropes, resulting in an increased secretion of immunoreactive adrenocorticotrophin (irACTH). Pituitary tissues from foetal sheep, of gestational ages 119-126 days, were examined by immunohistochemistry. Primary antibodies for prostaglandin $\mathrm{H}$ synthase- 1 and -2 (PGHS-1 and PGHS-2), microsomal prostaglandin
\end{abstract}

endoperoxide synthase (mPGES) and irACTH were used to probe expressed proteins and Alexa-Fluor red- and green-fluorescent secondary antibodies were used to visualise the bound primary antibody. Staining for PGHS-1, PGHS-2 and mPGES was found throughout the foetal anterior pituitary. PGHS-1 and mPGES were widely distributed, including but not restricted to corticotropes. PGHS-2 was less widely distributed but occasionally was found in cells adjacent to corticotropes. The results indicate that locally produced prostaglandins may have an influence on the secretion of ACTH, independent of placental $\mathrm{PGE}_{2}$.

Journal of Endocrinology (2004) 180, 303-310

\section{Introduction}

Foetal plasma cortisol concentration rises spontaneously during late gestation in the foetal sheep (Challis \& Brooks 1989). The increase in cortisol results in the activity of $17 \alpha$-hydroxylase (cytochrome $\mathrm{P}^{4} 50_{\mathrm{C} 17}$ ) in the placenta, allowing an increase in the concentration of oestrogen relative to the concentration of progesterone. The increased oestrogen-to-progesterone ratio increases myometrial tone and augments the contractility of the uterus (Liggins et al. 1973), and ultimately triggers labour and delivery. While the basic sequence of events which trigger labour is now known, the mechanism underlying the increase in activity of the foetal hypothalamus-pituitaryadrenal (HPA) axis is not. Exogenous prostaglandin $\mathrm{E}_{2}$ $\left(\mathrm{PGE}_{2}\right)$ stimulates HPA axis activity (Louis et al. 1976, Young \& Thorburn 1994). Inhibition of endogenous prostaglandin biosynthesis reduces the magnitude of HPA responses to hypotension in the foetus (Tong et al. 1998, Tong \& Wood 1999). Thorburn and others have proposed that $\mathrm{PGE}_{2}$ might play a critical role in the stimulation of HPA axis activity at the end of gestation. While $\mathrm{PGE}_{2}$ might play an important role in modulating foetal adrenocorticotrophin (ACTH) secretion, the source of prostaglandin affecting pituitary function in the foetus is controversial. We and others have demonstrated the presence of prostaglandin biosynthetic enzymes in the brain and pituitary (Breder et al. 1992, 1995, Tong et al. 1999, 2000, 2002, Deauseault et al. 2000). These enzymes include prostaglandin $\mathrm{H}$ synthase-1 and -2 (PGHS-1 and PGHS-2), which are involved in the conversion of $\mathrm{PGG}_{2}$ to $\mathrm{PGH}_{2}$, and microsomal prostaglandin endoperoxide synthase (mPGES), which is one of two known enzymes in the final enzymatic process in the production of $\mathrm{PGE}_{2}$. On the basis of these experiments, we have proposed that local biosynthesis of prostaglandins in the brain and/or pituitary modulates the activity of the HPA axis (Cudd \& Wood 1991, 1992).

Prostaglandins are known modulators of corticotrope function (Brooks \& Gibson 1992). Brooks and co-workers demonstrated that $\mathrm{PGE}_{2}$ increases the $\mathrm{ACTH}$ response to arginine vasopressin (AVP), but that it reduced the ACTH response to corticotrophin-releasing hormone $(\mathrm{CRH})$. In the sheep, both of these releasing factors act as secretagogues (Rose et al. 1985, Brooks \& Gibson 1992, Currie \& Brooks 1992). Local generation of $\mathrm{PGE}_{2}$ within or in 
close proximity of the corticotrope would therefore be expected to modulate corticotrope responsiveness to the hypothalamic releasing factors. The purpose of the present study was to test the hypothesis that either PGHS-1 or PGHS-2 is expressed within corticotropes in the foetal anterior pituitary. The secondary aim of these experiments was to test the hypothesis that $\mathrm{PGE}_{2}$ synthase is expressed in or adjacent to corticotropes which express either isoform of PGHS.

\section{Methods}

We studied pituitaries obtained from foetal sheep of known gestational age (123-140 days gestation). All of the pituitary tissue was obtained as a part of another study that was designed to investigate neuronal and pituitary expression of Fos (the protein product of the c-fos gene) in response to oestradiol administration and cerebral hypoperfusion (Purinton \& Wood 2002). Pituitaries used in the present study were from foetuses that had not been subjected to cerebral hypoperfusion. Each foetus was chronically instrumented with vascular catheters and an extravascular balloon occluder around the brachiocephalic artery. Nevertheless, the circulating ACTH and cortisol concentrations in these foetuses was appropriate for gestational age and the foetuses were not, therefore, chronically stressed.

Immediately after killing, the foetal brain and pituitary were perfused with 2 litres of heparinised saline, followed by 2 litres of 4\% paraformaldehyde. Tissue was processed for embedding by dehydration with progressively increasing concentrations of ethanol followed by xylene. Tissue was embedded in paraffin and cut into $5-7 \mu \mathrm{m}$ sections using a Zeiss HM-325 microtome. Sections were then mounted on poly-L-lysine-coated slides. Sections were deparaffinised with xylene. The sections were then rehydrated using successive 2-min rinses in 100, 90, 70, 50 and $25 \%$ solutions of ethanol in distilled and deionised water $\left(\mathrm{ddH}_{2} \mathrm{O}\right)$, followed by two washes in $\mathrm{ddH}_{2} \mathrm{O}$. Immunohistochemistry was performed using commercially available primary and secondary antisera. Primary antibodies included anti-ACTH (Zymed Co., San Francisco, CA, USA), anti-PGHS-1 and anti-PGHS-2 (Oxford Biomedical, Oxford, MI, USA) and anti-mPGES (Oxford Biomedical).

Tissue sections were blocked with $10 \%$ goat serum (Sigma) in PBS with $0 \cdot 2 \%$ Tween 20 for at least $10 \mathrm{~min}$. Sections were incubated with primary antisera for $30 \mathrm{~min}$ at room temperature, washed again with PBS, then incubated with secondary antibodies for $30 \mathrm{~min}$. After a final wash, the sections were coverslipped using Fluoromount (Zymed Co.). Secondary antisera were goat anti-rabbit IgGs conjugated with a green (Alexa Fluor 488; Molecular Probes, Eugene, OR, USA) or red (Alexa Fluor 594; Molecular Probes) fluorophore. Immunostaining was visualised using a Zeiss Axioplan 2 fluorescence microscope and/or a Bio-Rad 1024 ES confocal microscope in the McKnight Brain Institute Optical Microscopy Center (University of Florida, Bainesville, FL, USA). Each set of slides examined included negative controls for each primary antibody (i.e. slides were stained with one of the primary antibodies and without the other). These slides were visualised and photographed for both red and green secondary antibodies. Specific immunofluorescence was eliminated in the negative control slides.

\section{Results}

\section{Staining and co-localisation of ACTH with PGHS-1 and PGHS-2}

The distribution of corticotropes within the anterior pituitary was typical for foetuses of this gestational age $(\sim 120$ days). At low magnification, cells containing immunoreactive ACTH (irACTH) were found in clusters (Fig. 1A). Although no attempt was made to map the distribution of these clusters, the irACTH-positive cells were readily identifiable and were interpreted to be corticotropes. Islands and cords of immunoreactive cells were scattered throughout the anterior pituitary and appeared to be a mixture of adult-type (strongly reactive and cuboidal) and foetal-type (weaker reactivity and more elongated) corticotropes (Fig. 1).

PGHS-1 was found in a majority of cells within the anterior pituitary, including those positive for ACTH and those not positive for ACTH (Fig. 1B). As shown in Fig. $1 \mathrm{~B}$, most of the cells of the anterior pituitary were positive for PGHS-1 (red fluorescence, Fig. 1B). Cells colocalising immunoreactive PGHS-1 and irACTH were identified by the yellow-orange colour of the superimposed green (ACTH) and red (PGHS-1) fluorescence. Random samples were analysed using the confocal microscope, confirming co-localised staining within individual cells (data not shown).

PGHS-2 was found in fewer cells, generally in groups of cells scattered throughout the anterior pituitary (Fig. 1C). The intensity of the immunostaining for PGHS-2 was also not as high as the intensity of the PGHS-1 immunostaining. PGHS-2 was often found in cells in very close proximity to ACTH-producing cells, and occasionally these two were found within the same cell (Fig. 1C).

Cells within the neurointermediate lobe (NIL) are known to express pro-opiomelanocortin (POMC) and were readily identifiable using the anti-ACTH antiserum (Fig. 2A and B, green fluorescence). At high magnification, staining for PGHS-2 (Fig. 2A and B, red fluorescence) was seen within the cells of the NIL. Throughout the NIL, there was extensive immunostaining of immunoreactive ACTH and PGHS-2, although the immunostaining did not appear to directly overlap. 
The staining for irACTH within this lobe was probably POMC, $\alpha$-melanocyte-stimulating hormone ( $\alpha-\mathrm{MSH})$ and corticotrophin-like intermediate lobe peptide (CLIP).
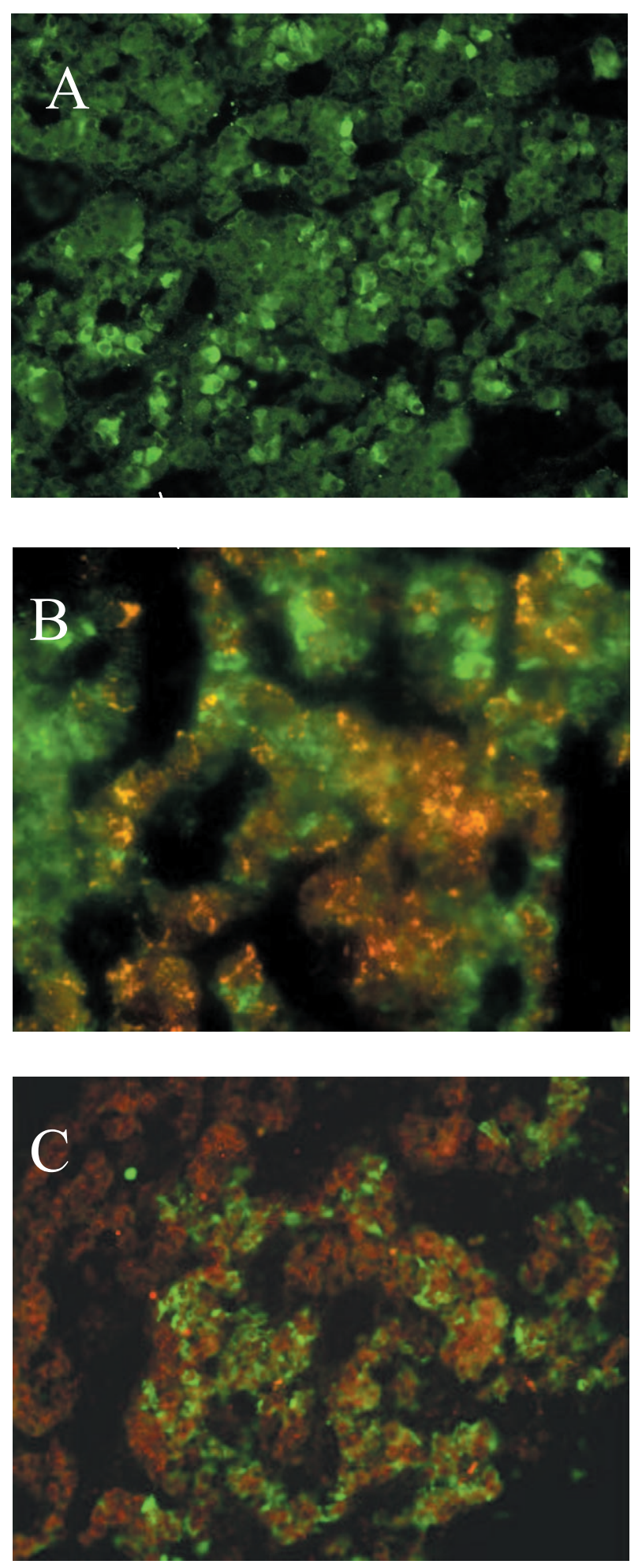

www.endocrinology.org
The posterior lobe (PL) was not specifically investigated in this study. However, in PL tissue adjacent to the anterior pituitary, we observed what appeared to be isolated islands of corticotropes (Fig. 2C). The endothelial cells lining the blood vessels within the PL stained very strongly for both PGHS-1 and PGHS-2 (Fig. 2D and E respectively).

Staining and co-localisation of mPGES with PGHS-1 and PGHS-2

mPGES immunostaining was widespread within the anterior pituitary. The degree of staining within the cells varied, some were very strong positives while others appeared only weakly reactive to this antibody (Fig. 3A, red fluorescence). As shown by the yellow colour of overlapping red (mPGES) and green (PGHS-1) fluorescence, mPGES was found co-localised with PGHS-1 in many cells (Fig. 3B). PGHS-2-positive cells (green fluorescence) and mPGES-positive cells (red fluorescence) were found in close proximity to each other, but rarely did the same cells stain for both (Fig. 3C). Nevertheless, there were occasional islands of cells in which mPGES and PGHS-2 co-localised, as illustrated by the yellow colour in Fig. 3C. mPGES did not seem to be abundant within the NIL (note the relative lack of red fluorescence in the NIL shown in Fig. 3F). Those cells that were positive for mPGES were very weak, and did not appear to be co-localised with either of the other enzymes.

\section{Co-localisation of ACTH and $m P G E S$}

In some sections, ACTH-positive cells were clustered near mPGES-positive cells (Fig. 3D), while in other sections ACTH and mPGES were co-localised (Fig. 3E). The staining of mPGES within the NIL was very weak, but appeared to be present in most cells. As shown in Fig. 3F, co-localisation of irACTH (green fluorescence) and immunoreactive mPGES (red fluorescence) was more common in the anterior pituitary than in the NIL. Staining of mPGES within the posterior pituitary was not apparent (not shown).

\section{Discussion}

The results of the present study strongly suggest that $\mathrm{PGE}_{2}$ is synthesised locally in the foetal anterior pituitary; the

Figure 1 Co-staining of immunoreactive ACTH and PGHS-1 or PGHS-2. (A) Immunoreactive ACTH (green fluorescence) in a group of corticotropes ( $\times 40$ magnification). (B) Immunoreactive PGHS-1 (red fluorescence), immunoreactive ACTH (green fluorescence) and co-staining of immunoreactive PGHS-1 and ACTH (yellow fluorescence, $\times 80$ magnification). (C) Immunoreactive PGHS-2 (red fluorescence), and immunoreactive ACTH (green fluorescence, $\times 80$ magnification). 

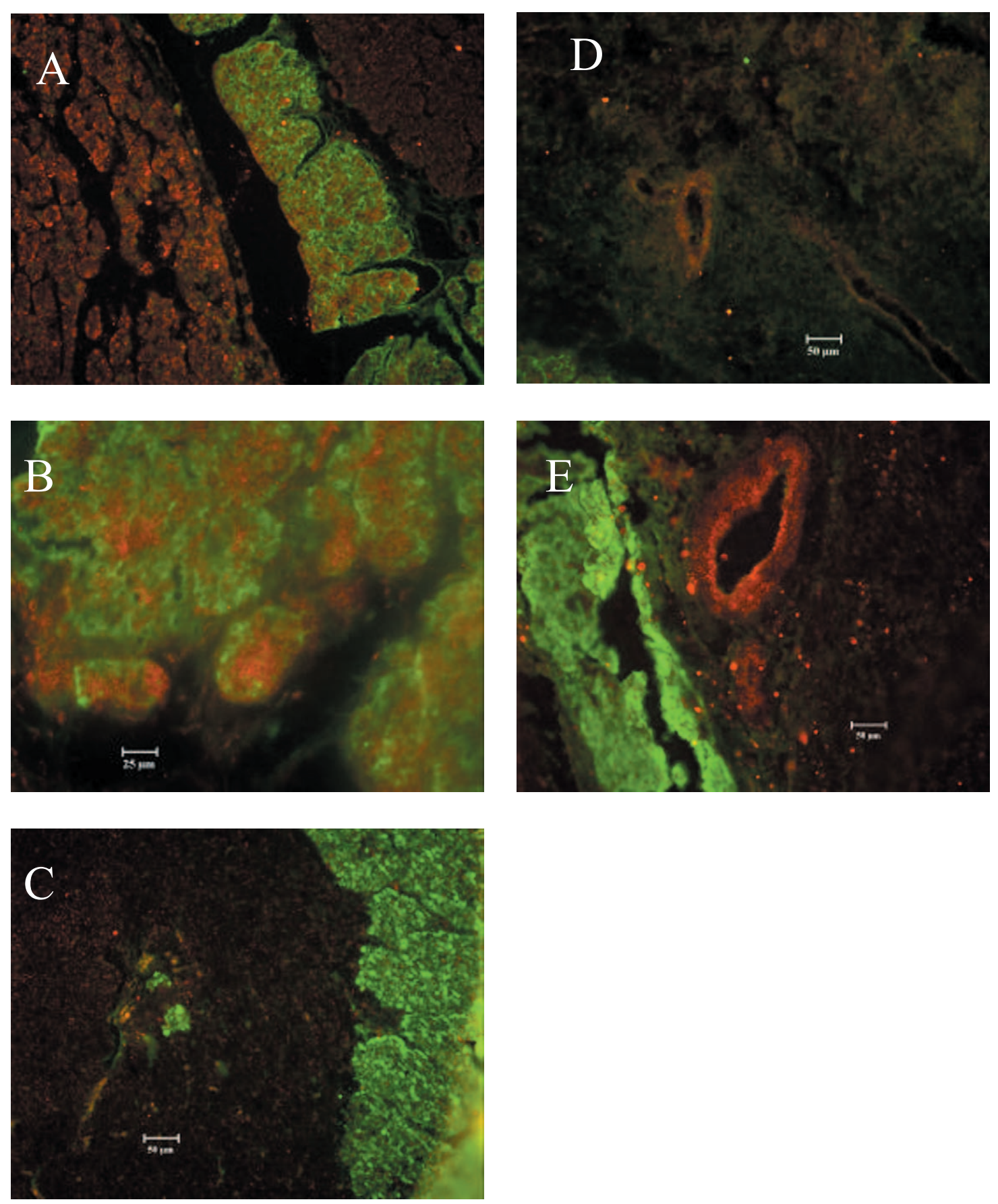

Figure 2 Co-staining of immunoreactive ACTH and PGHS-2 in neurointermediate lobe. (A) Immunoreactive ACTH (green fluorescence) and PGHS-2 (red fluorescence) in the NIL ( $\times 20$ magnification). (B) Immunoreactive ACTH (green fluorescence) and PGHS-2 (red fluorescence) in the NIL ( $\times 40$ magnification). (C) Immunoreactive ACTH (green fluorescence) in an apparent island of corticotropes within the posterior pituitary ( $\times 20$ magnification).

(D) Immunoreactive PGHS-1 (red fluorescence) in microvasculature $(\times 20$ magnification). (E) Immunoreactive PGHS-2 (red fluorescence) in microvasculature ( $\times 20$ magnification). 

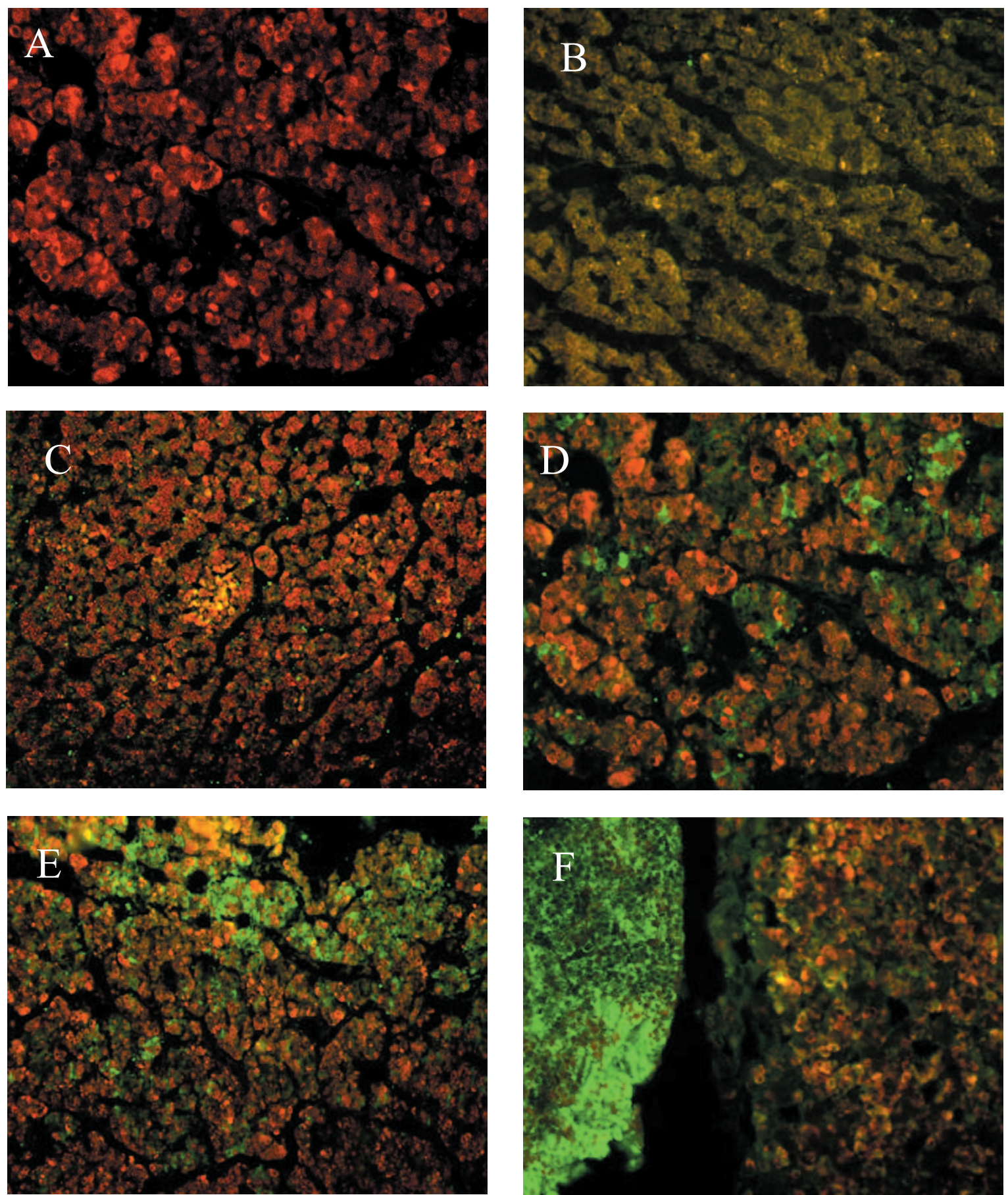

Figure 3 (A) Immunoreactive microsomal PGE synthase (mPGES, red fluorescence) in the anterior pituitary $(\times 40$

magnification). (B) Immunoreactive mPGES (red fluorescence) and immunoreactive PGHS-1 (green fluorescence). Nearly all of the immunostaining for these two proteins is co-localised within the same cell, indicated by the yellow fluorescence $(\times 40$ magnification). (C) Immunoreactive mPGES (red fluorescence) and immunoreactive PGHS-2 (green fluorescence). The Figure shows one island of cells which contained both proteins (yellow fluorescence, $\times 20$ magnification). (D) Immunoreactive mPGES (red fluorescence) and immunoreactive PGHS-2 (green fluorescence). Compare with (A), which is the same section showing only mPGES immunoreactivity ( $\times 40$ magnification). (E) Immunoreactive mPGES (red fluorescence) and immunoreactive ACTH (green fluorescence, $\times 20$ magnification). (F) Immunoreactive mPGES (red fluorescence) and immunoreactive ACTH (green fluorescence, $\times 20$ magnification); cells expressing both proteins are indicated by the yellow fluorescence; in this section, the $\mathrm{NIL}$ and the immunoreactive ACTH-containing cells of the NIL are clearly visible (left). 
late-gestation ovine foetal anterior pituitary expresses PGHS-1, PGHS-2 and mPGES. The distribution of the enzymes suggests that $\mathrm{PGE}_{2}$ can be synthesised in foetal corticotropes, probably as a result of the action of PGHS-1 and mPGES. The effect of prostanoids and prostanoid inhibitors on the ability to modulate the release of ACTH from the pituitary has been examined at both hypothalamic and pituitary levels. There is convincing evidence that metabolites of arachadonic acid can modulate the secretory response to CRH (Cowell et al. 1991) and AVP (Brooks 1992, Brooks \& Gibson 1992). Studies performed in vitro (Vlaskovska \& Knepel 1984, Abou-Samra et al. 1986, Wilson \& Guild 2002) and in vivo (Hedge 1977) have shown that inhibition of $\mathrm{PGE}_{2}$ and/or injection of $\mathrm{PGE}_{2}$ has a direct modulatory effect on corticotropes.

Ovine parturition is initiated by an increase in the activity of the HPA axis. Prior to parturition, there is an increase in the circulating concentrations of ACTH (Rose et al. 1978, Wintour et al. 1975) and cortisol (Bassett \& Thorburn 1969), as well as an increase in the mass and responsiveness of the foetal adrenal to ACTH (Durand et al. 1981, 1982, 1984, Boshier \& Holloway 1991). Disruption of the axis at any level defeats or delays the initiation of parturition. Cutting the infundibular stalk (Antolovich et al. 1990), lesion of the paraventricular nuclei (McDonald \& Nathanielsz 1991), and destruction of the pituitary itself (Liggins et al. 1967) can all delay parturition in sheep. Thorburn and colleagues have demonstrated that $\mathrm{PGE}_{2}$ circulates in foetal plasma, and that the concentrations of $\mathrm{PGE}_{2}$ increase prior to parturition (Challis et al. 1976, Fowden et al. 1987, Deayton et al. 1993). The primary source of the circulating $\mathrm{PGE}_{2}$ is the placenta, and the activity of PGHS in the placenta increases proportionately as a function of foetal gestational age (Rice et al. 1990, 1992). Thorburn and colleagues have also demonstrated that exogenous $\mathrm{PGE}_{2}$ stimulated ACTH secretion (Hollingworth et al. 1995) and that continuous intravenous infusion of $\mathrm{PGE}_{2}$ into the foetus can stimulate premature parturition. These observations support Thorburn's proposal that $\mathrm{PGE}_{2}$, released by the placenta in increasing concentrations prior to parturition, is a stimulus to the foetal HPA axis and that it is the 'drive' from the $\mathrm{PGE}_{2}$ that ultimately triggers parturition (Young \& Thorburn 1994).

Experiments performed in this and other laboratories, however, have suggested that local production of prostaglandins might be more important than circulating sources. We have demonstrated that infusion of $\mathrm{PGE}_{2}$ into the carotid arteries did stimulate foetal ACTH secretion, but only at concentrations which exceeded those produced by placental secretion (Cudd \& Wood 1992). In a separate study, Brooks found that $\mathrm{PGE}_{2}$, delivered either intravenously or intracerebroventricularly, increased $\mathrm{ACTH}$ secretion in foetal sheep (Brooks 1992). It is possible that $\mathrm{PGE}_{2}$ delivered intravenously acts at the pituitary gland to augment the corticotrope response to hypothalamic releasing factor. Intracerebroventricular injections of $\mathrm{PGE}_{2}$ probably mimic neuronal or glial synthesis of $\mathrm{PGE}_{2}$. In previous experiments, we have used the technique of microdialysis to find that brainstem and hypothalamic interstitial fluid concentrations of $\mathrm{PGE}_{2}$ are increased during hypotension. We and others have found that the foetal brain contains significant amounts of both isoforms of PGHS (Tong et al. 1999, Deauseault et al. 2000). Blockade of the synthesis of $\mathrm{PGE}_{2}$ with indomethacin greatly attenuates the HPA response to hypotension (Tong et al. 1998).

The foetal pituitary secretes ACTH in response to stimulation by either AVP or CRF. The corticotrope response to these two hormones changes as a function of gestational age/maturity of the foetus (Norman \& Challis 1987, Brooks \& Gibson 1992). In the foetal pituitary, $\mathrm{PGE}_{2}$ acts synergistically with AVP to produce a greater increase in the production of irACTH from the anterior pituitary than does AVP alone (Brooks \& Gibson 1992). Interruption of the hypothalamic-pituitary stalk ablates the response of the pituitary (secretion of ACTH) to the infusion of $\mathrm{PGE}_{2}$, suggesting that $\mathrm{PGE}_{2}$ may act at the hypothalamic level (Young et al. 1996), or that it acts by augmenting the ACTH response to endogenous releasing factors. We propose that prostanoids, including but not restricted to $\mathrm{PGE}_{2}$, are synthesised within the foetal pituitary and act in a paracrine or autocrine manner to modify the corticotrope response to $\mathrm{CRH}$ and AVP. Although we have focused our present efforts on the biosynthetic enzymes required for $\mathrm{PGE}_{2}$ synthesis, it is possible that other prostanoids or PGHS products are important, as well. For example, we have found that U46619, the thromboxane $A_{2}$ mimetic, stimulated foetal ACTH secretion. This drug was more effective when infused into the carotid arteries as compared with infusion into the vena cava (Wood et al. 1993). This suggests that thromboxane acted at some site within the region perfused by the carotid vasculature (potentially the anterior pituitary) to stimulate ACTH secretion. The anterior pituitary contains immunoreactive thromboxane synthase (Wood et al. 1997, Tong et al. 1999). On the other hand, there are no data available concerning the potential influence of thromboxane $\mathrm{A}_{2}$ on corticotrope function.

The development of corticotropes within the anterior pituitary shows a progressive maturation from a 'foetal' type, which predominates at 115 days gestational age, to an 'adult' type which predominates at 135 days (Perry et al. 1985). The 'foetal' type shows less intense staining for ACTH immunoreactive cells, which are large and columnar in shape, and arranged in clumps or palisades; in contrast, the adult-type has more intense staining, they occur individually or in small clusters, are usually angular and occasionally have cellular processes enveloping adjacent cells (Perry et al. 1985, Antolovich et al. 1989). Maturation of the foetal pituitary is also reflected in 
ontogenetic changes in responsiveness to AVP. Durand and co-workers reported that corticotrope responsiveness to AVP was reduced in vitro at 133 and 144 days gestation compared with younger foetuses. In that study, responsiveness to CRH was not changed. In vivo, on the other hand, responsiveness to both AVP and CRH were decreased in the 135-140 day gestation foetus, but this was possibly due to the elevated foetal plasma cortisol concentration at that time (Durand et al. 1986, Norman \& Challis 1987). The morphology of the tissue examined in the present study is consistent with the previously published results. The pituitary tissue used in this study was from foetuses between 123 and 140 days gestation, and the majority of the corticotropes appeared to be consistent in morphology and staining intensity with the 'adult'-type corticotropes, although the overall abundance of the corticotropes in these foetal pituitaries was far greater than in adult ovine pituitaries prepared and analysed similarly (Reimsnider and Wood, unpublished observations). Because of the specific range of foetal gestational ages used in this study, it is important to recognise that the patterns of co-expression of ACTH, PGHS-1, PGHS-2 and mPGES might have been different in younger foetuses. Nevertheless, we chose this age for study because it is the foetal gestational age at which the activity of the HPA axis is rapidly increasing, approximately 2 weeks prior to the initiation of labour (Rose et al. 1978, 1981, Challis \& Brooks 1989).

In summary, we conclude that the prostaglandin biosynthetic enzymes are expressed in the foetal pituitary which would allow local biosynthesis of, and autocrine or paracrine action of, $\mathrm{PGE}_{2}$ or other prostanoids. Additional work will be required to assess the importance of this biosynthesis in vivo, exclusive of an effect of changes in circulating $\mathrm{PGE}_{2}$ concentrations. Nevertheless, the results of this study suggest that the local biosynthesis of prostanoids might play a physiologically relevant role in the control of foetal ACTH secretion.

\section{Funding}

This work was supported by HD42135 from the National Institutes of Health to C E W.

\section{References}

Abou-Samra AB, Catt KJ \& Aguilera G 1986 Role of arachidonic acid in the regulation of adrenocorticotropin release from rat anterior pituitary cell cultures. Endocrinology 119 1427-1431.

Antolovich GC, Perry RA, Trahair JF, Silver M \& Robinson PJ 1989 The development of corticotrophs in the fetal sheep par distalis: the effect of adrenalectomy or cortisol infusion. Endocrinology 124 1333-1339.

Antolovich GC, Clarke IJ, McMillen IC, Perry RA, Robinson PM, Silver M \& Young R 1990 Hypothalamo-pituitary disconnection in the fetal sheep. Neuroendocrinology 51 1-9.
Bassett JM \& Thorburn GD 1969 Foetal plasma corticosteroids and the initiation of parturition in sheep. Journal of Endocrinology 44 285-286.

Boshier DP \& Holloway H 1991 Morphometric analyses of adrenal gland growth in fetal and neonatal sheep. III. Volumes of the major organelles within zona fasciculata and steroidogenic cells. Journal of Anatomy, London 178 175-187.

Breder CD, Smith WL, Raz A, Masferrer J, Seibert K, Needleman P \& Saper CB 1992 Distribution and characterization of cyclooxygenase immunoreactivity in the ovine brain. Journal of Comparative Neurology 322 409-438.

Breder CD, DeWitt DL \& Kraig RP 1995 Characterization of inducible cyclooxygenase in rat brain. Journal of Comparative Neurology 355 296-315.

Brooks AN 1992 Prostaglandin E2 stimulates adrenocorticotrophin and cortisol secretion via a hypothalamic site of action in fetal sheep. Journal of Developmental Physiology 18 173-177.

Brooks AN \& Gibson F 1992 Prostaglandin E2 enhances AVP-stimulated but not CRF-stimulated ACTH secretion from cultured fetal sheep pituitary cells. Journal of Endocrinology 132 33-38.

Challis JRG \& Brooks AN 1989 Maturation and activation of hypothalamic-pituitary-adrenal function in fetal sheep. Endocrine Reviews 10 182-204.

Challis JRG, Dilley SR, Robinson JS \& Thorburn GD 1976 Prostaglandins in the circulation of the fetal lamb. Prostaglandins $\mathbf{1 1}$ 1041-1052.

Cowell AM, Flower RJ \& Buckingham JC 1991 Studies on the roles of phospholipase $\mathrm{A}_{2}$ and eicosanoids in the regulation of corticotrophin secretion by rat pituitary cells in vitro. Journal of Endocrinology 130 21-32.

Cudd TA \& Wood CE 1991 Does intracarotid PGE2 increase plasma ACTH concentration in conscious adult ewes. American Journal of Physiology 261 E395-E401.

Cudd TA \& Wood CE 1992 Prostaglandin E2 releases ovine fetal ACTH from a site not perfused by the carotid vasculature. American Journal of Physiology 263 R136-R140.

Currie IS \& Brooks AN 1992 Corticotrophin-releasing factors in the hypothalamus of the developing fetal sheep. Journal of Developmental Physiology 17 241-246.

Deauseault D, Giroux D \& Wood CE 2000 Ontogeny of immunoreactive prostaglandin endoperoxide synthase isoforms in ovine fetal pituitary, hypothalamus, and brainstem. Neuroendocrinology $71287-291$.

Deayton JM, Young IR \& Thorburn GD 1993 Early hypophysectomy of sheep fetuses: effects on growth, placental steroidogenesis and prostaglandin production. Journal of Reproduction and Fertility $\mathbf{9 7}$ 513-520.

Durand P, Caithiard AM, Morera AM, Dazord A \& Saez J 1981 Maturation of adrenocorticotropin-sensitive adenylate cyclase of ovine fetal adrenal during late pregnancy. Endocrinology 108 2114-2119.

Durand P, Caithiard AM \& Saez J 1982 In vitro maturation of ovine fetal adrenal cells adenylate cyclase: corticotropin-dependent and independent development of the response to corticotropin. Biochemical and Biophysical Research Communications 106 8-15.

Durand P, Cathiard A \& Saez JM 1984 In vitro maturation of steroidogenic capacity of ovine fetal and neonatal adrenal cells. Endocrinology 114 1128-1134.

Durand P, Cathiard AM, Dacheux F, Naaman E \& Saez JM 1986 In vitro stimulation and inhibition of adrenocorticotropin release by pituitary cells from ovine fetuses and lambs. Endocrinology 118 $1387-1394$.

Fowden AL, Harding R, Ralph MM \& Thorburn GD 1987 The nutritional regulation of plasma prostaglandin $\mathrm{E}$ concentrations in the fetus and pregnant ewe during late gestation. Journal of Physiology 394 1-12. 
Hedge GA 1977 Stimulation of ACTH secretion by indomethacin and reversal by exogenous prostaglandins. Prostaglandins 14 145-151.

Hollingworth SA, Deayton JM, Young IR \& Thorburn GD 1995 Prostaglandin E2 administered to fetal sheep increases the plasma concentration of adrenocorticotropin (ACTH) and the proportion of ACTH in low molecular weight forms. Endocrinology $\mathbf{1 3 6}$ 1233-1240.

Liggins GC, Kennedy PC \& Holm LW 1967 Failure of initiation of parturition after electrocoagulation of the pituitary of the fetal lamb. American Journal of Obstetrics and Gynecology 98 1080-1086.

Liggins GC, Fairclough RJ, Grieves SA, Kendall JZ \& Knox BS 1973 The mechanism of initiation of parturition in the ewe. Recent Progress in Hormone Research 29 111-159.

Louis TM, Challis JRG, Robinson JS \& Thorburn GD 1976 Rapid increase in fetal corticosteroids after prostaglandin E2. Nature $\mathbf{2 6 4}$ 797-799.

McDonald TJ \& Nathanielsz PW 1991 Bilateral destruction of the fetal paraventricular nuclei prolongs gestation in sheep. American Journal of Obstetrics and Gynecology 165 764-770.

Norman LJ \& Challis JRG 1987 Synergism between systemic corticotropin-releasing factor and arginine vasopressin on adrenocorticotropin release in vivo varies as a function of gestational age in the ovine fetus. Endocrinology 120 1052-1058.

Perry RA, Mulgvogue HM, McMillen IC \& Robinson PM 1985 Immunohistochemical localization of ACTH in the adult and fetal sheep pituitary. Journal of Developmental Physiology 7 397-404.

Purinton SC \& Wood CE 2002 Oestrogen augments the fetal ovine hypothalamus-pituitary-adrenal axis in response to hypotension. Journal of Physiology 544 919-929.

Rice GE, Wong MH, Hollingworth SA \& Thorburn GD 1990 Prostaglandin G/H synthase activity in ovine cotyledons: a gestational profile. Eicosanoids 3 231-236.

Rice GE, Payne MJ, Wong MH \& Thorburn GD 1992 Immunoreactive prostaglandin $\mathrm{G} / \mathrm{H}$ synthase content increases in ovine cotyledons during late pregnancy. Placenta 13 429-437.

Rose JC, Macdonald AA, Heymann MA \& Rudolph AM 1978 Developmental aspects of the pituitary-adrenal axis response to hemorrhagic stress in lamb fetuses in utero. Journal of Clinical Investigation 61 424-432.

Rose JC, Meis P \& Morris M 1981 Ontogeny of endocrine (ACTH, vasopressin, cortisol) responses to hypotension in lamb fetuses. American Journal of Physiology 240 E656-E661.

Rose JC, Hargrave BY, Dix PM, Meis PJ, Lafave M \& Torpe B 1985 Corticotropin-releasing factor-induced adrenocorticotropic hormone release in the sheep fetus. American Journal of Obstetrics and Gynecology 151 1128-1133.

Tong H \& Wood CE 1999 Indomethacin attenuates the cerebral blood flow response to hypotension in late-gestation fetal sheep. American Journal of Physiology 277 R1268-R1273.
Tong H, Lakhdir F \& Wood CE 1998 Endogenous prostanoids modulate the ACTH and AVP responses to hypotension in late-gestation fetal sheep. American Journal of Physiology 275 R735-R741.

Tong H, Richards E \& Wood CE 1999 Prostaglandin endoperoxide synthase-2 abundance is increased in brain tissues of late-gestation fetal sheep in response to cerebral hypoperfusion. Journal of the Society of Gynecological Investigation 6 127-135.

Tong H, Dhillon H \& Wood CE 2000 Induction of PGHS-2 mRNA in response to cerebral hypoperfusion in late-gestation fetal sheep. Prostaglandins and Other Lipid Mediators 62 165-172.

Tong H, Gridley KE \& Wood CE 2002 Induction of immunoreactive prostaglandin $\mathrm{H}$ synthases 1 and 2 and fos in response to cerebral hypoperfusion in late-gestation fetal sheep. Journal of the Society of Gynecological Investigation 9 342-350.

Vlaskovska M \& Knepel W 1984 Beta-endorphin and adrenocorticotropin release from rat adenohypophysis in vitro: evidence for local modulation by arachidonic acid metabolites of the cyclooxygenase and lipoxygenase pathways. Neuroendocrinology 39 334-342.

Wilson ML \& Guild SB 2002 A direct inhibitory action of prostaglandins upon ACTH secretion at the late stages of the secretory pathway of AtT-20 cells. British Journal of Pharmacology 135 1851-1858.

Wintour EM, Brown EH, Denton DA, Hardy KJ, McDougall JG, Oddie CJ \& Whipp GT 1975 The ontogeny and regulation of corticosteroid secretion by the ovine foetal adrenal. Acta Endocrinologica 79 301-316.

Wood CE, Cudd TA, Kane C \& Engelke K 1993 Fetal ACTH and blood pressure responses to thromboxane mimetic U46619. American Journal of Physiology 265 R858-R862.

Wood CE, Purinton S \& Cudd TA 1997 Immunoreactive thromboxane synthase is measurable in ovine fetal hypothalamus as early as 86 days' gestation. Prostaglandins 54 569-579.

Young IR \& Thorburn GD 1994 Prostaglandin E2, fetal maturation and ovine parturition. Australian and New Zealand Journal of Obstetrics and Gynaecology 34 342-346.

Young IR, Deayton JM, Hollingworth SA \& Thorburn GD 1996 Continuous intrafetal infusion of prostaglandin E2 prematurely activates the hypothalamo-pituitary-adrenal axis and induces parturition in sheep. Endocrinology 137 2424-2431.

Received 18 September 2003

Accepted 3 October 2003 